\title{
Engineering Education Problems in Context of Post-Industrial Society
}

\author{
Irina Tsvetkova, and Tatyana Ivanova \\ Togliatti State University, Togliatti, Russia
}

\begin{abstract}
The paper analyzes social aspects of engineering education in the context of modern industrial society. The engineering education is important for Russia due to the start of the sixth wave of innovation which results in industry modernization and involves new technologies. Engineering education in accordance with modern production demands is becoming interdisciplinary issue. Not only scholars but also representatives of Russian business and management have an interest in the solution of the named problem. The authors of existing scientific works stress the need to develop new pedagogical approaches and learning technologies in the training of engineers. The use of information technology, the development of communication skills and project activities are becoming crucial. Reforms of higher technical education are aimed at developing the creative potential of students. The formation of motivation for engineering education is becoming of great importance among young people. The article analyzes the results of a sociological study on the students' opinions on the learning environment and their prospective professional activity. Problems of students' motivation and their professional self-realization come to the fore. The solution of the named problem depends on the interaction effectiveness of higher education institutions, the business community and state structures.
\end{abstract}

Since 2010, the Russian government has proclaimed the need to move to the sixth wave of innovation. This stage of development involves the development of robotics, nanotechnology, global information networks, artificial intelligence systems and biotechnologies. Yet, most Russian enterprises are currently in the third, fourth or even the first stage of the fifth wave while the industry development and introduction of advanced manufacturing technologies is carried out, mainly, at the enterprises of the militaryindustrial complex [1].

One of the important factors of technical and technological development of the country is professional training of qualified engineering personnel. In the post-Soviet period, a number of conflicting trends have emerged in this sphere. On the one hand, there is increasing society's demand

erdisciplinary and applied sciences such as medical engineering, social engineering, genetic engineering, etc. are rapidly developing. Information technologies provide new opportunities for engineering students in the field of programming and communications. This trend in its turn leads to the creation of new undergraduate programs and types of employment. According to the forecasts, today's university students will change their work place more than ten times within twenty years of their employment record. Thus, educational institutions today train professionals for jobs that are still in the making or have not been even created.

Modern training of engineering personnel has faced a challenge from a rapid technological change. In the conditions of the modern labor market, an innovative of well qualified engineering personnel to face the economy challenges. Enterprises need highly qualified specialists in the field of engineering and technology. On the other hand, employers make steep demands to graduates of engineering departments [2]. So, the existing situation has brought to the forefront a need to resolve the urgent problems of the labor market and the ability of higher education institutions to fulfill this goal. In this situation the needs and interests of young people in acquiring technical professions and professional self-realization are becoming of great importance [3].

Scientific and technological development at the present stage introduces new requirements for the training of engineers. These requirements are caused by emerging of new fields in mechanical engineering. At present new int approach to the training of engineering personnel is becoming of great importance.

Engineering pedagogy faces an important task of updating traditional paradigms of teaching and searching for new approaches to educational technologies [4].

Different researchers define the present stage of Russian engineering education development as a socio-technological one. The existing need for a curriculum enhancement is caused by the lack of coordination between the higher education system and the labor market. The students are given fundamental training in the natural sciences while the engineering labor market is characterized by increasing demand for professionals with practical skills mostly.

Modern educational programs should be based on interactive forms of training. Improving the quality of

Corresponding author: aleksandr.kozlov@mail.ru 
engineering education heavily depends on the introduction of new educational technologies [5]. They include the use of project methods and tools that simulate an accurate model of the real-world situation [6].

Engineering education is often defined as "complex" due to both the large scope of natural science disciplines in the curriculum and the need for good mathematical training [7]. The complexity of engineering education is associated with interdisciplinary connections, which are necessary for the quality of graduates. Interdisciplinary education provides a broad outlook, development of various cultural contexts and it enables students to interact effectively with representatives of different cultures, to overcome the one-sidedness of technical training [8]. Interdisciplinary in modern conditions is realized in conditions of curriculum differentiation. The logical move from one academic discipline to another is not obvious for most students and, consequently, there arises the problem of forming an integral picture of knowledge and ideology in general.

Technical education at present is characterized by the fact that $80 \%$ of vocational training is carried out at a particular workplace, rather than at an educational institution. This trend is typical not only for the Russian higher school, but also for higher education in other countries. The analyses of the current situation allows suggesting that the integration of vocational training and professional activities will be observed as typical in the near future. The students will be not only the consumers of educational services, but also their customers and developers.

The professional activity of engineers in modern conditions is integrated with other non-technical activities. According to foreign studies, engineers spend as much as $60 \%$ of their time for meetings, preparation of reports and other documents. Engineers devote only $40 \%$ of the time to the activities directly related to the technical development. So, the solution of many problems of modern engineering education is related to the need for interdisciplinary approaches.

In the context of globalization, specialists from different countries often carry out the implementation of technical projects as the products can be made in different regions of the world. The international supply chain determines technical and technological resources. Therefore, training of engineers includes the acquisition of skills of intercultural communication with representatives of different countries, as noted by E.N. Pishcherskaia, V.P.Filippova [9]. A modern engineer should have good communication skills, be able to work with representatives of different cultures, have the skills in logistics and project management. Higher education is to become more flexible and mobile; it should meet the needs of modern production facilities. One of the ways to solve the problem is to use information technology in the process of engineering training. This trend in education modernization requires the transformation of methods of engineering and technical specialists training as well as the creation of new pedagogical theories and technologies for solving the urgent problems of engineering education [10].

For Russian technical universities there exists one more problem connected with the purchase of modern equipment for laboratories and practical classes. This is important as engineers at the production site will have to work with imported equipment and the solution of this problem largely depends on the state support of technical universities [11].

The research conducted by British scholars B. Lucas and J. Hanson is aimed at analyzing the specific features of the technical way of thinking. The scientists believe that it is systematic and aimed at creative problem solving, visualization, improvement and adaptation. Consequently, the training of future engineers should include the targeted development of these skills at all levels and stages of training. The solution of these problems requires the search for new approaches in the teaching of technical disciplines [12]. Modern standards of engineer training suggest making conditions for the development of a creative potential of every student [13].

This problem is relevant for all countries that are engaged in the training of engineering personnel. American researchers J. Rodriguez and I.E. Esparragoza note the importance of the students participation in technical projects. The subject of their analysis is the motivation for the future engineers' participation in international projects. There are some difficulties connected to the students' need to adapt to the socio-cultural characteristics of participants from different countries. The researchers note that cultural diversity is an additional incentive for obtaining deeper technical knowledge within their major of study. The researchers also note that females show greater interest in the implementation of projects at all stages than males [14].

In the context of globalization, there arises a problem of the diversity of engineering training in regards of the sociocultural peculiarities of various social groups and it becomes urgent for the training of engineering personnel. The researchers focus on organization of training of engineering personnel in different countries, on problems of gender equality in engineering teams, problems of cultural diversity and inclusiveness while conducting technical research. For example, an international conference was held in Switzerland in 2015 to discuss the diversity of approaches to engineering education with respect to gender equality [15].

German researchers Y. Sedelmaier and D. Landes emphasize the effectiveness of the competence approach to the training of students at technical universities. According to the researchers, this approach is based on modeling the problem situation in the classroom. Groups of students of 57 people are given a task in the form of a project. The students carry out a self-conducted search of information, discuss the difficulties that arise within the group. This approach to learning, according to the researchers, is more efficient than the traditional form of theory studies [16].

Foreign researchers pay much attention to the technique of teaching technical disciplines using modern technologies. German scholars M. Vasko, S. Ritter, G. Metzger studied the impact of the internet and digital technologies on the engineering students learning achievements. The results of the research demonstrate a positive association between the students' decision to do their homework online and the final test performance. The researchers note that the use of suitable tasks for students with different levels of preparation can not affect students' motivation for learning mathematics. One of the urgent issues in this field is developing independent learning skills to improve students' confidence in working independently [17]. This is one of the major challenges to solve in modern engineering pedagogy. 
Higher education institutions annually produce thousands of young people with higher education diplomas in engineering. However, enterprises still face the problems of aging personnel and a shortage of young professionals. This problem is also relevant for Togliatti. Since the middle of the last century, Togliatti has been growing in the conditions of rapid industrial development, which resulted in the emergence of large industrial enterprises. During this period, an educational system was created to train workers and engineers for the technical sphere of this region. In modern conditions of transition to a new technological way, there arise problems with the development of HR potential of Togliatti enterprises. Among the reasons for the decline in the prestige of engineering professions researchers note economic, socio-cultural and organizational reasons.

The study of a professional group of engineers and technicians has deep traditions in the Russian sociology. The sociologists have been analyzing this professional sphere since the 1960s. The focus was on the professional stratification of engineers and technicians, the content of their labor [18]. Under current circumstances, it is of great significance to analyze the professional training of young engineers, the motivation for professional activity to be formed at the university [19].

The attitude of young people to engineering and technical specialties became the subject of a sociological survey conducted by the students and teachers of Togliatti State University in 2016.

The survey was conducted among the students of the Institute of Mechanical Engineering. 256 people were interviewed, among them 137 first-year students and 119 fourth-year students. This model of research makes it possible to study the differences between groups of respondents in the notions of their attitudes toward engineering professions. Two-thirds of the respondents are state-subsidized students and $39 \%$ of the respondents are fee-paying students.

In the course of the study, there was received information on factors influencing students' choice of engineering major. $48 \%$ of respondents reported that they were influenced by their parents' advice. Following the friends' advice is reported in $38 \%$ of the questionnaires. $26 \%$ of survey participants reported an interest in working with technology as a motive for choosing an engineering major. The same is the proportion of respondents who indicated the opportunity to get fully funded scholarship. An important factor is the transport accessibility of the educational institution; it was reported by $28 \%$ of the respondents. $14 \%$ of survey participants believe that they have propensities and abilities for engineering profession. $16 \%$ of respondents noted as the significant factor the prestige of the chosen profession. Despite appeals made by the Government, the prestige of the chosen engineering profession is less important to students and this figure remains low. At the same time the example and advice of parents when selecting the major is of great importance for the students.

The students were also asked about the difficulties they encountered during training. More than half of the respondents $(53 \%)$ note the problems they have while studying some subjects, $48 \%$ of respondents have problems in their relations with some teachers. First-year students face the named difficulties about one and a half times more often than the average for the array. $44 \%$ of survey participants consider the educational content of some subjects to be boring. The first-year students observe this problem by $10 \%$ more often and by the students in senior courses - less often. A quarter of respondents faced difficulties in completing a large number of practical (laboratory) tasks. The first-year students note this variant of the answer about twice as often as the average for the array. $14 \%$ of respondents have difficulty in preparing course projects. $2 \%$ of survey participants consider the organization of internship to be ineffective.

Of great importance for the effective training of future engineers is the participation of students in research and development. $46 \%$ of students assess the conditions created at the University for doing scientific work as satisfactory. $42 \%$ of students consider the conditions mostly satisfactory. $4 \%$ of respondents noted that conditions created at the university are rather unsatisfactory. Only $5 \%$ of respondents rate these conditions as completely unsatisfactory. $3 \%$ of respondents found it difficult to answer the question posed.

As a result of the research it was found that $46 \%$ of students take part in research activities. Thus, $54 \%$ of survey participants are not engaged in this activity. This distribution is typical for both junior and senior students. For students participating in research work, higher results of academic performance are characteristic. Among them 65\% of respondents have high rates of achievement, and among those who do not participate in scientific work - only $43 \%$. There are more females participating in scientific associations than males.

In the course of the research, there was identified the students' command of research skills on a scale: "I have a good command" - "I have some skills" - "I have a bad command".

$41 \%$ of students reported that they are good at selection and analysis of theoretical material. $32 \%$ of respondents have the skills of calculations. $18 \%$ of participants of the survey reported to have practical skills in conducting a research. Only $8 \%$ of students reported to have good skills in writing scientific publications. So, the results of the survey show that the students' research skills are mainly manifested in analyzing theoretical works.

The survey provided information on students' participation in the scientific events. $54 \%$ of students take part both in Olympiads and in conferences. 32\% of respondents participate in scientific conferences only. $24 \%$ of survey participants participate in exhibitions. $17 \%$ of respondents present scientific publications on the results of their research. $16 \%$ of respondents participated in the competitions of the best research works. $8 \%$ of respondents received a scientific grant. Thus, approximately $30 \%$ of the respondents are active participants in scientific events and they can present the results of their research. At the same time more than half of the respondents act as passive participants in the scientific events. $16 \%$ of respondents report that they have not participated in any scientific event at all.

Mastering the skills of research work causes a number of difficulties for the students. The results of numerous scientific studies show that many students experience considerable difficulties in organizing research activities - namely during the research, while writing scientific publications and presenting the reports. $84 \%$ of respondents believe that the university could not provide conditions that were sufficiently 
attractive for motivating students to take part in research activities. As it turned out, $76 \%$ of students have a low level of readiness for conducting a research, $16 \%$ - medium and only $8 \%$ - high level.

The opinions of students on the importance of research activities in vocational training are presented as follows. $44 \%$ of respondents reported that the scientific work ensures their professional knowledge and skills and it gives an opportunity to communicate with interesting people. $38 \%$ of respondents believe that the scientific work makes it possible to participate in creative activities and to realize their potential. $14 \%$ of survey participants believe that the scientific work forms the skills of preparing scientific publications.

Approximately $19 \%$ of respondents say that participation in scientific activities gives them opportunity to receive increased scholarship and to visit other cities for presenting their works at the scientific events. According to $12 \%$ of survey participants, research work is an integral part of «a good student image". The research-related activities are believed to prepare the student for doing a Master's degree. $16 \%$ of respondents believe that scientific work is a crucial admission criterion to Master's degree. At the same time $15 \%$ of survey, participants reported participation in scientific work as the factor to contribute to key performance indicators. Less than $10 \%$ of students marked the following options for answers: public recognition (obtaining diplomas, gifts); opportunity to spend time usefully; enhancing their self-esteem. Thus, approximately $40 \%$ of respondents believe that participation in scientific work has practical benefits for their further education or for mastering their prospective trade.

When asked about the students' views about the core activities of their future job, the following answers were received. Half of the respondents is well aware of their future professional performance, $29 \%$ of respondents have a poor vision of it. $14 \%$ of survey participants have a vague idea of their future job. $7 \%$ of respondents believe that the primary aim is to graduate from the university and they have not thought about their professional activities. The difference in the answers between the first and second year students is not great. Thus, only half of the students majoring in engineering have a clear idea about their future professional activity.

When analyzing the results of the survey, the students' opinions on the attractive aspects of the engineering profession were studied. Two-fifths of the survey participants indicated the opportunity to be useful to people. Approximately the same number of respondents reported decent salary prospects as an attractive factor for their choice of engineering major. $29 \%$ of respondents noted the probability of working in the chosen field after graduation and occupational growth forecasts. $28 \%$ of students are attracted by the possibility of ensuring the safety of people when working with machinery. $23 \%$ of the survey participants indicate the creating new technology, increasing the efficiency of technical devices, engagement in invention and rationalization among the attractive aspects of engineering major. $19 \%$ of survey participants believe that majoring in engineering makes it possible to start their own business. $14 \%$ of respondents would like to start management careers. $10 \%$ of survey participants named favorable conditions of work as an attractive factor.
The survey participants were asked: "Do you like the chosen major?". $73 \%$ of respondents answered "rather yes", $18 \%$ of respondents hold the opposite opinion, $9 \%$ of respondents found it difficult to answer the question. The first-year students by $5 \%$ more often give a positive answer to the question whether they like the chosen major; this is more than the average for the array. On the contrary, the fourth-year students by $5 \%$ less often express a positive attitude toward engineering profession; also the number of fourth-year students who find it difficult to answer the given question increases by $5 \%$.

An analysis of the results of the questionnaire shows that about $30 \%$ of respondents do not form a positive attitude toward the engineering profession while studying at the university. The number of those who find it difficult to answer the question about their attitude to the engineering profession does not decrease, but on the contrary increases.

In the course of the survey, the respondents' opinions on the prospects of chosen engineering profession in the future were studied. The results for the array are as follows: $28 \%$ of respondents would like to work in the chosen profession, first-year students are by $18 \%$ more likely to choose this option than the average for the array, $40 \%$ of respondents plan to work in the related field, $28 \%$ of survey participants are not going to work in their engineering field. This last variant of the answer was chosen by the students of the fourth year by one and a half times more often than the average for the array.

The survey data show that the first year students express an intention to work in their specialty more often than others. Among graduate students the desire to work in the engineering field is less pronounced. Perhaps this is due to the fact that the graduates face difficulties in finding a job in their field, so they make a decision to search for alternative ways of professional self-determination.

One of the research tasks was to study the students' ideas about their future professional career. $61 \%$ of survey participants would like to become high-qualified specialists. $54 \%$ of respondents reported that they want to find a highly paid and prestigious job. $34 \%$ of those surveyed plan to move to another city and settle in the best way there. $44 \%$ of respondents plan to take a managerial position. $28 \%$ of respondents plan to start their business. And $15 \%$ of respondents say that the most important professional goal is to obtain recognition and fame in the sphere of their professional activity.

According to the opinion of the graduates, the career in the sphere of industrial production depends on a high level of knowledge, work experience and professionalism. Such qualities as sociability, initiative, self-reliance, ability to understand people, in their opinion, are less important.

In the conditions of modern Russian society, the choice young professionals make in professional sphere is not final. It depends on the job security and existing opportunities for work in the professional field. The research data showed that $61 \%$ of respondents consider their choice of profession to be final. $32 \%$ of students doubt the opportunities to be employed in this sphere, and $7 \%$ of respondents are initially set for a long search for themselves in the process of acquaintance with various professions. Thus, in modern conditions, most students focus on the choice of a professional sphere, in which they plan their employment, rather than a particular profession. 
The results of the sociological survey testify to the existence of a number of contradictions that are manifested at the level of engineering students' self-consciousness. On the one hand, their choice of profession is motivated by the interest in technology, by the desire to improve it and increase its efficiency. Students' choice of occupation is also attributed by the parental influence for major choice. Many students argue that technical professions benefit society. Technical education is seen as useful and in demand. At the same time, the motivation for choosing the major is not related to deep understanding of students' personality. Only $14 \%$ of students believe that they have the ability, the inclination to work with technology. To increase the effectiveness of engineering education it is important to identify the features of technical way of thinking and its development among young people.

To improve the quality of engineering education, the participation of students in research work is of great importance. The results of the survey show that less than half of the students participate in the scientific projects. This can be also explained by the fact that poor material and technical base of the university affects the opportunities for students to participate in this type of activity. Half of the students have clear vision of their future professional activities in the technical field. The desire to pursue a profession is often expressed by the first-year students. Students of the fourth year are more often oriented to work in the fields related to engineering. Many students believe that the engineering profession gives an opportunity to become a useful specialist for society. However, when analyzing employment problems there emerges a different picture. Working conditions, technical equipment of enterprises and wages of engineers leave much to be desired. Thus, the problem of training engineering personnel for the sixth wave of innovation in this country cannot be solved by the efforts of universities only. Great importance can be attributed to the development of effective methods of teaching technical disciplines, to the students' participation in research and development.

The results show that there are contradictions between the existing reality and the students' expectations which are related to the creative activity aimed at technology improvement. Many of the students believe that engineers do not have to deal with unemployment problems and they hope to receive high wages for tech jobs. In reality, these positive aspects of engineering professions look different.

The given problem is complex; it is connected with the search of effective forms of interaction of higher education institutions, the business community and state structures.

\section{References}

1. V. M. Averbukh, VSSU 71,160 (2010)

2. S. I. Gerasimov, V. G. Ivanov, A. P., Svetlakov, S. O. Shaposhnikov, VKTU 16,105 (2013)

3. M. N. Bulaeva, A. V. Lapshova, KNJ 4, 23 (2017)

4. J. Raven, BGJ 3, 255 (2017)

5. V. I. Burenina ANI: Pedagogy and Psychology 3, 47 (2017)

6. M. M. Mukhamedzhanov V. V. Kalinov, Power 6, 44 (2012)

7. I.K. Kondaurova, BHJ 3, 51 (2015)
8. Y. V. Artukovic, A. A. Soloviev BGU. Series 7: Philos. Sociol. and soc. Tech. 2, 152 (2013)

9. E. N.Pishcherskaia , V. P. ANI: Ped.and Psych.4, 189 (2016)

10. M. Auer Michael, D. Dobrovska, A. Edwards, E. Likl, HER 2, 40 (2013)

11. O. V. Grigorash, NJ KubGAU 91, 1913 (2013)

12. B. Lucas, J. Hanson, , iJEP 6, 4 (2016)

13. H. P. Kirillov, Yu. S. Plotnikov, V. N. Fadeeva, VNS 1, 408 (2011)

14. J. Rodriguez, I.E. Esparragoza, iJEP 7, 89 (2017)

15. D.A. Delaine, R. Tull, R. Sigamoney, D. N. Williams, iJEP, 6, 56 (2016)

16. Y. Sedelmaier, D. Landes iJEP 5, 34 (2015)

17. M. Vasko, S. Ritter, G. Metzger, iJEP 8, 40, (2018)

18. M. V. Zhuhai, SA 8,156 (2017)

19. N.P. Baharev, KNJ 4, 40 (2014) 